\title{
Brachial Plexus Palsy Related to Birth
}

National Cancer Institute

\section{Source}

National Cancer Institute. Brachial Plexus Palsy Related to Birth. NCI Thesaurus. Code C102990.

Birth injury to the brachial plexus. It results in paralysis of the muscles of the shoulder, arm, and hand. It manifests as lack of mobility in the arm, usually in the first week of life. In the majority of cases there is spontaneous recovery. 